\title{
Influence of the compression rate at various temperatures on the functional properties of the NiTi shape memory alloy
}

\author{
E. S. Ostropiko ${ }^{\dagger, 1}$, A. Yu. Konstantinov ${ }^{2}$ \\ †es-ostropiko@mail.ru \\ ${ }^{1}$ Saint Petersburg State University, St. Petersburg, 199034, Russia \\ ${ }^{2}$ Lobachevsky State University of Nizhny Novgorod, Nizhny Novgorod, 603950, Russia
}

The functional properties of shape memory alloys depend on the strain rate. However, there is no systematic investigation of the basic functional properties after high strain rate deformation; most of the published articles, including modern studies, focus on the mechanical properties and structure. This paper presents a study of the influence of strain rate on the one-way and two-way shape memory effects. The specimens were compressed at strain rates of 500, 1200, $1600 \mathrm{~s}^{-1}$ in the martensitic, austenitic, and mixed-phase state, using the Kolsky method for the split Hopkinson pressure bar. The one-way and two-way shape memory effects were measured after dynamic compression and compared with ones after quasi-static compression up to the same residual strains. The work shows that the strain rate has significant influence on the basic functional properties of the NiTi alloy. In some cases, the strain-temperature curves after the quasi-static and dynamic compression were completely different. The one-way shape memory effect after high-strain rate compression was less than after quasi-static compression, irreversible strain increased. After high-strain rate compression in the martensitic state, the martensitic two-way shape memory effect slightly grows, but in general, there is no significant improvement. The austenitic two-way shape memory effect after high strain rate compression occurred at lower test temperatures, and its value was higher than after quasi-static compression. Thus, in some cases, the functional properties of the NiTi alloy can be improved by an increase in the strain rate. The material behavior indirectly demonstrates that the reorientation of martensite and the formation of stress-induced martensite are sensitive to the strain rate.

Keywords: shape memory alloy, high strain rate, one-way shape memory effect, two-way shape memory effect, split Hopkinson-Kolsky bar.

УДК: 669.018, 539.38

\section{Влияние скорости сжатия при различных температурах на функциональные свойства сплава с памятью формы NiTi}

\author{
Остропико Е.С. ${ }^{\dagger, 1}$, Константинов А. Ю. ${ }^{2}$ \\ ${ }^{1}$ Санкт-Петербургский Государственный Университет, С.-Петербург, 199034, Россия \\ ${ }^{2}$ Нижегородский государственный университет имени Н. И. Лобачевского, Нижний Новгород, 603950, Россия
}

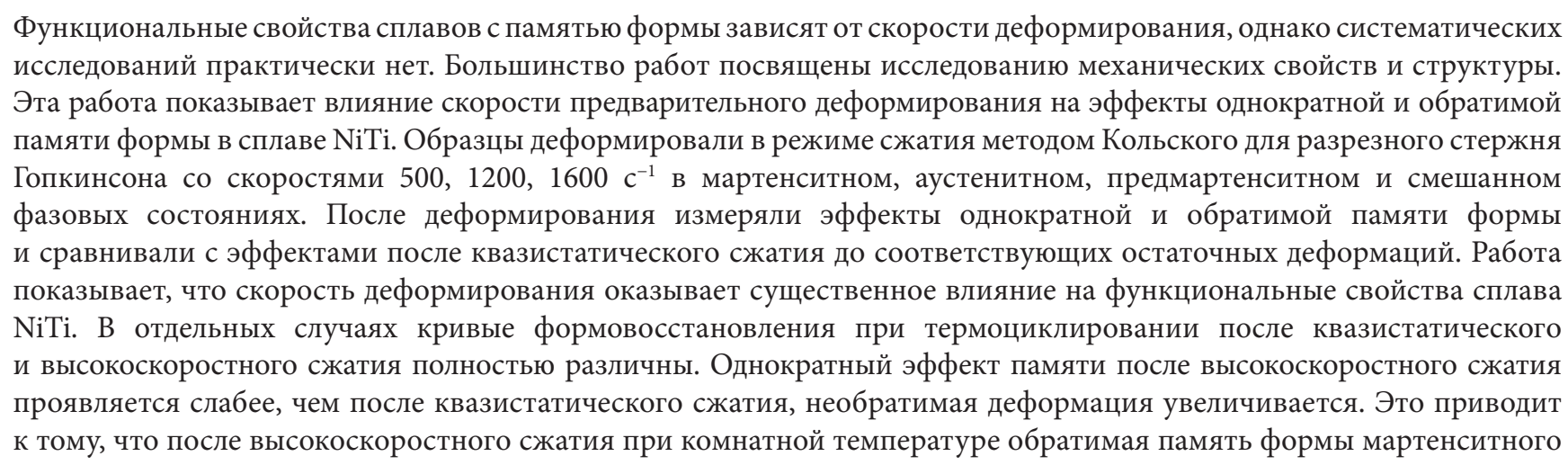


типа слегка растет, но в целом существенного улучшения не наблюдается. Обратимая память формы аустенитного типа после высокоскоростного сжатия появляется при более низких температурах предварительного деформирования и проявляется сильнее, чем после квазистатического сжатия. То есть, в отдельных случаях функциональные свойства сплава можно улучшить за счет увеличения скорости деформирования. Поведение материала косвенно демонстрирует, что процессы переориентации и наведения мартенсита под нагрузкой чувствительны к скорости нагружения.

Ключевые слова: сплавы с памятью формы, высокоскоростное деформирование, эффект памяти формы, обратимая память формы, метод Кольского.

\section{Introduction}

Shape memory alloys (SMA) have a number of unique properties: high strength, corrosion resistance, biocompatibility and damping ability. Moreover, they have functional capabilities to recover from large deformations resulting from solid-tosolid phase transformation: the one-way (SME) and two-way (TWSM) shape memory effects. They are used in various areas: medicine [1], aerospace technology [2], and engineering [3] as stents, implants, sensors, actuators, and so on. One of the most commonly used SMA is nickel titanium (NiTi).

The mechanical and functional properties of materials depend on the deformation technique and the strain rate. However, there are only a few published papers devoted to the functional properties of SMA after high strain rate deformation. For some reason, researchers focus on studying the influence of the strain rate on the mechanical properties and structure of martensite and austenite [4-6], including recent investigations [7-10]. For example, in [9], the authors showed the influence of preliminary annealing on the mechanical behavior of the NiTi alloy under dynamic compression. In [10] they tested specimens of the NiTi alloy by high-strain rate compression at room temperature and at $100^{\circ} \mathrm{C}$ and showed the influence of the strain rates on the structure of the low-temperature (martensitic) and high-temperature (austenitic) phases, but they did not study the functional properties. In [11], the authors studied the influence of the strain rate on the mechanical behavior of a pseudoelastic NiTi alloy. The investigation of pseudoelasticity may be considered as an investigation of functional properties [11-13], since this effect is directly related to the forward and reverse martensitic transformations.

Among the works devoted to the SME and TWSM, the studies of Russian and Chinese researchers $[14,15]$ should be mentioned. However, they used the recovery coefficients the ratios of the SME and TWSM strains to the residual and irreversible strain and made conclusions based on these ratios, not on the values of the SME and TWSM effects themselves.

Based on the above, we can conclude that there are almost no systematic investigations of SMA basic functional properties after high strain rate deformation. Researchers almost keep ignoring the functional properties of the NiTi alloy, but investigate the mechanical properties, superelasticity, characteristic temperatures of martensite transformations, and the microstructure of martensite and austenite.

This work presents an investigation of the influence of high strain rate compression at various temperatures on the basic functional properties of the NiTi alloy: the one-way and two-way shape memory effects.

\section{Methods}

The objects of the study were cylindrical specimens of an equiatomic NiTi alloy with a diameter and height of about $8 \mathrm{~mm}$, made on a CNC Lathe from hot-rolled NiTi bars, annealed at $500^{\circ} \mathrm{C}$ for 1 hour to remove residual stresses, and furnace cooled. Characteristic temperatures were determined on a Mettler Toledo 822e differential scanning calorimeter: $M_{s}=78^{\circ} \mathrm{C}, M_{f}=55^{\circ} \mathrm{C}, A_{s}=89^{\circ} \mathrm{C}, A_{f}=110^{\circ} \mathrm{C}$ (Fig. 1).

Deformation was carried out at various temperatures: $20,103,130,87,63^{\circ} \mathrm{C}$ (Fig. 1). Test temperatures of 20, 103, $130^{\circ} \mathrm{C}$ were reached by heating and $87,63^{\circ} \mathrm{C}$ were reached by cooling after preliminary heating to $140^{\circ} \mathrm{C}$. Further we denote these temperatures as $140 \rightarrow 87^{\circ} \mathrm{C}$ and $140 \rightarrow 63^{\circ} \mathrm{C}$. We chose the test temperatures so that the material was in different phase states: in the martensitic state at $20^{\circ} \mathrm{C}$, in the austenitic state at $130^{\circ} \mathrm{C}$, in the austenitic but "premartensitic" state at $140 \rightarrow 87^{\circ} \mathrm{C}$ and in the mixed-phase state at 103 and $140 \rightarrow 63^{\circ} \mathrm{C}$ (peak temperatures of the calorimetry curve).

High strain rate tests were performed using the Kolsky method for the split Hopkinson pressure bar [16]. This method is well studied, theoretically justified, and has been well known since the 1950s. The setup consists of a gas gun with a control system, measuring bars, a striker and a set of measuring equipment [17]. The measuring bars with a diameter of $20 \mathrm{~mm}$ were made of high-strength maraging steel. The strain was measured using low-base foil strain gauges glued on the side surface of the measuring bars. Strain pulses were used to find the forces acting on the specimen and the history of the displacements of the specimen surface, using formulas proposed by Kolsky. More details about the Kolsky method and its modifications can be found in [17]. The setup was equipped with a thermocouple and a tubular removable furnace, which allowed testing at elevated temperatures. The

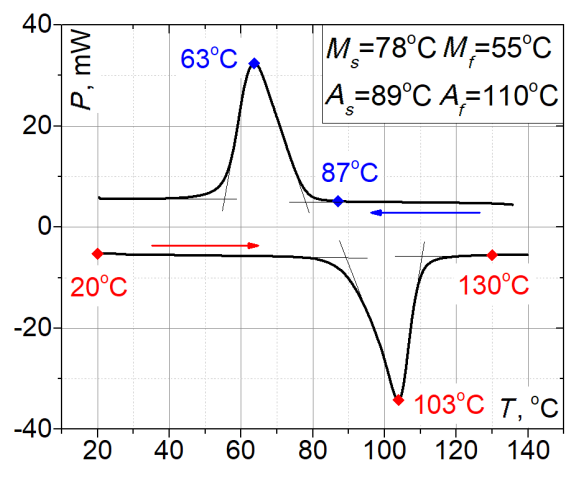

Fig. 1. (Color online) Calorimetric curves of the NiTi alloy: - test temperatures that were reached by heating, - test temperatures that were reached by cooling from $140^{\circ} \mathrm{C}$. 
strain rate varied by changing the gas gun pressure: a change in pressure led to a change in the striker velocity. The residual strains $\left(\varepsilon_{\text {res }}\right)$ varied depending on the strain rates. They were $\approx 5,10$, and $17 \%$ after compression at strain rates of 500,1200 , and $1600 \mathrm{~s}^{-1}$, respectively. Quasi-static compression at a strain rate of $0.001 \mathrm{~s}^{-1}$ of similar specimens to the same $\varepsilon_{\text {res }}$ (to one decimal place) was performed at the same test temperatures using an INSTRON universal testing machine, equipped with a thermal chamber. After deformation, all specimens were cooled to room temperature. After tests, we thermocycled the specimens through the temperature ranges of forward and reverse martensite transformations on a Netzsch TMA 402 F1 Hyperion thermomechanical analyzer. We measured the strains caused by the SME on the first heating and by the TWSM on the second heating from the changes in the height of the specimens.

The shapes of the strain-temperature curves $\varepsilon(T)$ during thermocycling depend on the preliminary deformation temperature. Two types of the TWSM are possible: martensitic and austenitic [18]. The TWSM arises after incompatible irreversible strain, which generates internal stresses. These stresses cause the formation of oriented martensite upon cooling. Thus, on the subsequent thermal cycling, a martensitic or austenitic TWSM is observed. The first one appears after preliminary deformation in the martensitic state (Fig. 2a). The first heating leads to the one-way shape memory effect, and the subsequent thermocycling leads to the martensitic TWSM, in which the strain changes upon cooling in the same direction as under pre-straining. The austenitic TWSM is observed after preliminary deformation in the austenitic state (Fig. 2b). During cooling, the strain changes in the direction opposite to the pre-strain. The implementation of these two types of TWSM in the same temperature range results in the formation of a non-monotonic reversing TWSM [19].

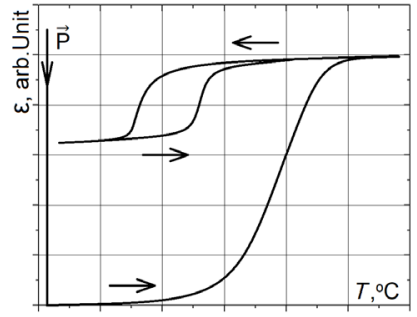

a

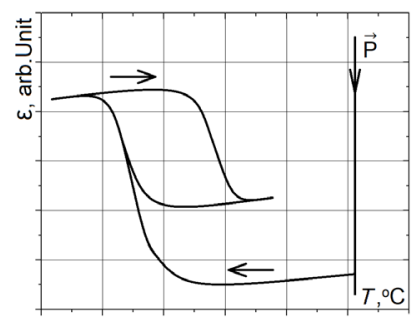

b

Fig. 2. Schematic of $\varepsilon(T)$ curves. $P$ shows the direction of the preliminary deformation: SME and martensitic TWSM after compression in the martensitic state (a), austenitic TWSM after compression in the austenitic state (b).

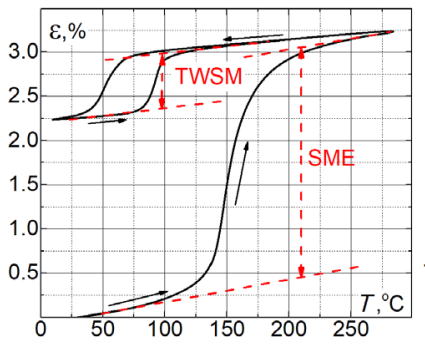

a

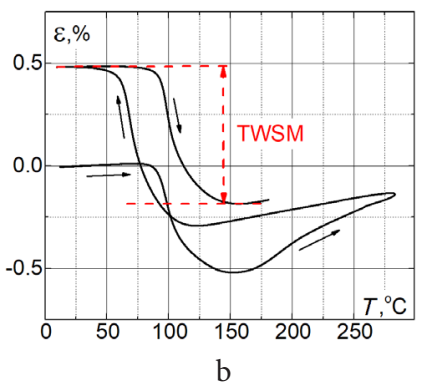

In this study, we observed both TWSM effects. Fig. 3 shows the strain-temperature curves after dynamic compression at $20,130,103$, and $140 \rightarrow 87^{\circ} \mathrm{C}$. Fig. 3 a demonstrates the SME during the first heating and the martensitic TWSM during the second heating. The austenitic TWSM appears after compression at $130^{\circ} \mathrm{C}$ (Fig. $3 \mathrm{~b}$ ). The values of SME and TWSM of both types we measured as the distance between the tangent lines, as shown in Fig. 3 a, b.

Unusual strain-temperature dependences were observed when the specimens were in the mixed or premartensitic phase state during preliminary loading (Fig. $3 \mathrm{c}, \mathrm{d}$ ). The contribution of both phases to the strain recovery leads to the appearance of a non-monotonic reversing shape memory effect. The $\varepsilon(T)$ curves consist of two oppositely directed sections during the first heating. Section I is associated with the austenitic TWSM that arises due to the deformation of the austenitic phase, and section II is associated with the SME that occurs due to the deformation of the martensitic phase. We considered the contribution of these sections in the total strain recovery separately. The second heating leads to the austenitic TWSM.

\section{Results and discussion}

\subsection{One-way shape memory effect}

Fig. 4 shows the values of the one-way shape memory effect measured in the first thermocycle after compression with various strain rates at different temperatures. The solid marks represent the SME after dynamic compression and the hollow marks represent the SME after quasi-static compression. The blue marks indicate the test temperatures reached by cooling.

The diagrams show that the hollow marks are above the solid marks: an increase in the strain rate does not lead to an increase in the shape memory effect. The closest values were obtained after deformation in the martensitic state at $20^{\circ} \mathrm{C}$, but an increase in the strain rate up to $1600 \mathrm{~s}^{-1}$ leads to a decrease in the SME by $25 \%$ (Fig. 4 c).

Martensite transformation is thermoelastic: stress can induce martensite. Loading in the mixed-phase, premartensitic and austenitic states leads to the formation of oriented stress-induced martensite, so subsequent thermocycles cause the SME and the martensitic TWSM (Fig. $5 \mathrm{a}, \mathrm{c}$ ). Under loading in the austenitic state at $130^{\circ} \mathrm{C}$, the proportion of stress-induced martensite decreases, that leads to small values of the SME (Fig. 4).

With an increase in the strain rate, the strain-temperature curves become completely different (Fig. 5b,d). The SME
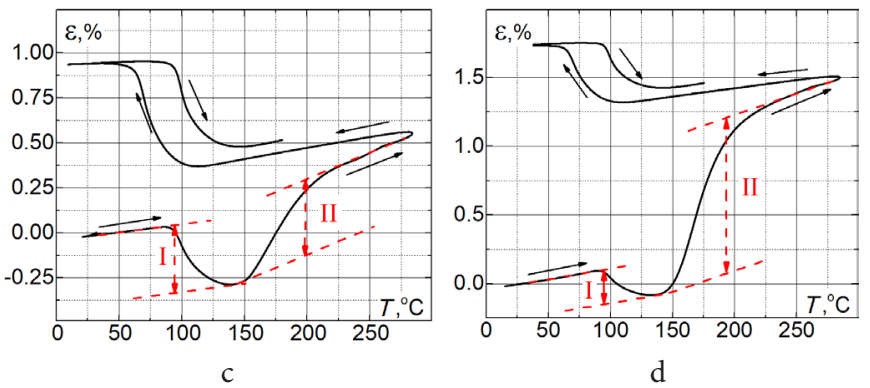

Fig. 3. $\varepsilon(T)$ curves after dynamic compression at a strain rate of $1200 \mathrm{~s}^{-1}$ up to $10 \%$ residual strain at $20^{\circ} \mathrm{C}(\mathrm{a}), 130^{\circ} \mathrm{C}(\mathrm{b}), 103^{\circ} \mathrm{C}(\mathrm{c})$, $140 \rightarrow 87^{\circ} \mathrm{C}$ (d). (I - austenitic TWSM, II - SME). 


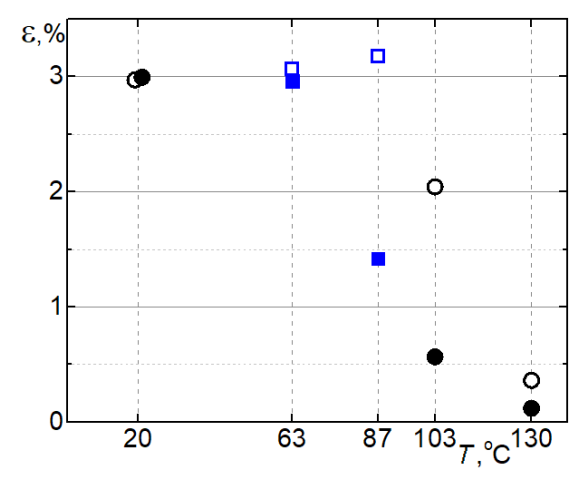

a

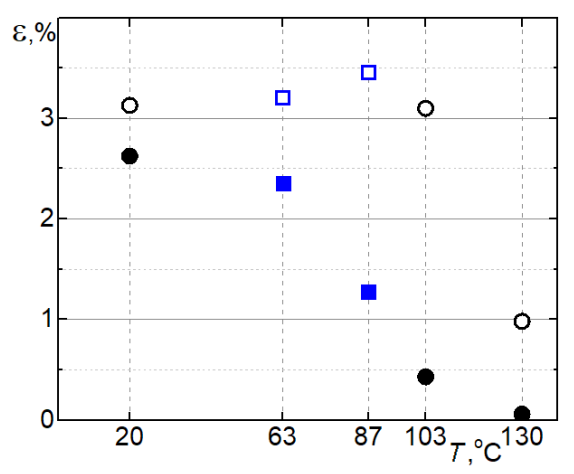

b

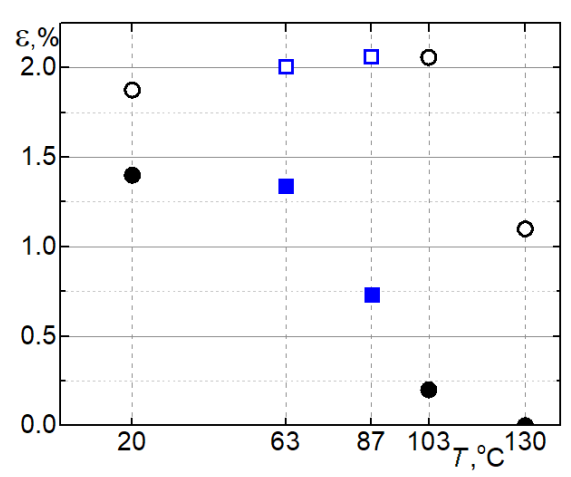

C

Fig. 4. Dependences of SME on test temperature. $\bigcirc, \square-$ quasi-static compression $\bullet$, $\mathbf{\square}$ - dynamic compression. 5\% residual strain, dynamic compression at a strain rate of $500 \mathrm{~s}^{-1}$ (a); $10 \%$ residual strain, dynamic compression at a strain rate of $1200 \mathrm{~s}^{-1}$ (b); $17 \%$ residual strain, dynamic compression at a strain rate of $1600 \mathrm{~s}^{-1}(\mathrm{c})$.

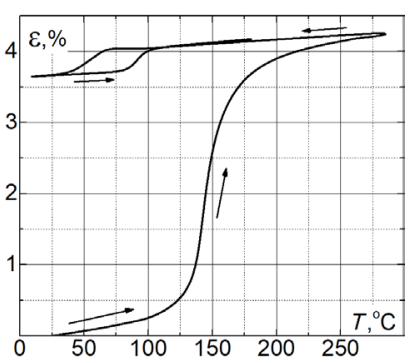

a

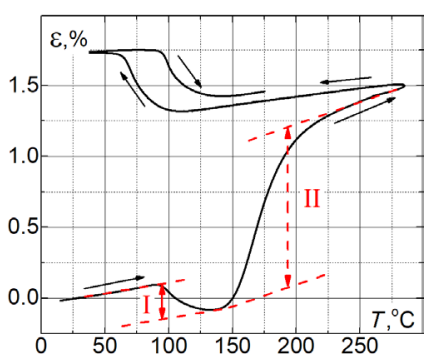

$\mathrm{b}$

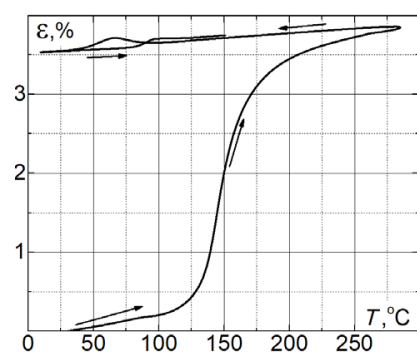

c

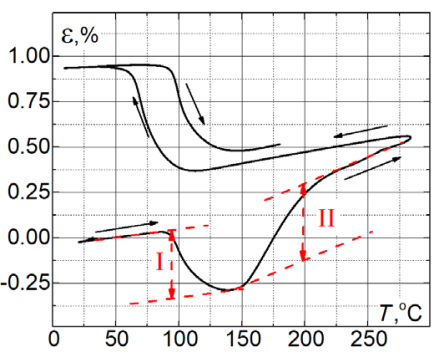

d

Fig. 5. $\varepsilon(T)$ curves after compression at $140 \rightarrow 87^{\circ} \mathrm{C}(\mathrm{a}, \mathrm{b})$ and $103^{\circ} \mathrm{C}(\mathrm{c}, \mathrm{d})$ up to $10 \%$ residual strain. Quasi-static (a, c) and dynamic (b, d) compression. (I - austenitic TWSM, II - SME).

during the first heating decreases and the second heating leads to the austenitic TWSM.

These differences in the SMA behavior during thermocycling are related only to the strain rate, since all other parameters (test temperature, residual strain, thermocycling conditions) are the same. It is assumed that the reversible strain due to the martensite reorientation and the formation of the stress-induced martensite is sensitive to the strain rate. Under the high strain rate compression more strain is produced by irreversible straining mechanisms compared to the quasi-static compression.

\subsection{Two-way shape memory effect}

Fig. 6 shows the TWSM values measured in the second cycle of heating. The "positive" points on the diagrams above the zero line correspond to the martensitic TWSM, the "negative" points below the zero line correspond to the austenitic TWSM. The blue color marks the temperatures reached by cooling.

The martensitic TWSM behavior looks similar to the SME behavior, except for the case of room temperature. The TWSM arises from internal stresses that appear due to the incompatibility of the irreversible strain. These internal stresses lead to the transformation-induced plasticity during direct martensitic transformation. Under loading in the martensitic state $\left(20^{\circ} \mathrm{C}\right)$, strain is conventionally divided into two types: reversible strain associated with martensite reorientation, and irreversible plastic strain. Under the condition of equal preliminary residual strains, if the SME decreases, then the irreversible strain increases. With an increase in the strain rate, the SME decreases. Consequently, with an increase in the irreversible strain, the martensitic TWSM slightly increases (by about $10-12 \%$ ).

The austenitic TWSM after dynamic compression occurs at lower temperatures. Moreover, the increase in the strain rate has a positive effect on the values of the austenitic TWSM. Diagrams show that an increase in the strain rate at $130^{\circ} \mathrm{C}$ leads to an increase in the austenitic TWSM in comparison with the quasi-static case. The austenitic TWSM increases by $15-25 \%$ at small residual strains (Fig. $6 \mathrm{a}, \mathrm{b}$ ), and almost three times at large residual strains (Fig. 6c) after the high strain rate compression.

As described above, the austenitic TWSM appears after deformation of the austenite. Quasi-static compression at elevated temperatures leads to the intensive formation of the stress-induced martensite that gives origin to the SME section during the first heating, for example see $\varepsilon(T)$ curve after quasi-static compression at $130^{\circ} \mathrm{C}$ (Fig. 7). Both deformed phases, martensite, and austenite, form internal stresses, which counteract each other during cooling. Because of this, the value of the strain induced during the direct martensitic transformation, and consequently, the austenitic TWSM is smaller than after dynamic compression. Such intensive formation of stress-induced martensite does not occur in the case of dynamic pre-straining. Moreover, in the quasi-static case, the fraction of the stress-induced martensite increases with an increase in the residual strain from 5 to $17 \%$, so the austenitic TWSM decreases almost twice from 0.55 to $0.28 \%$ (Fig. 6). 

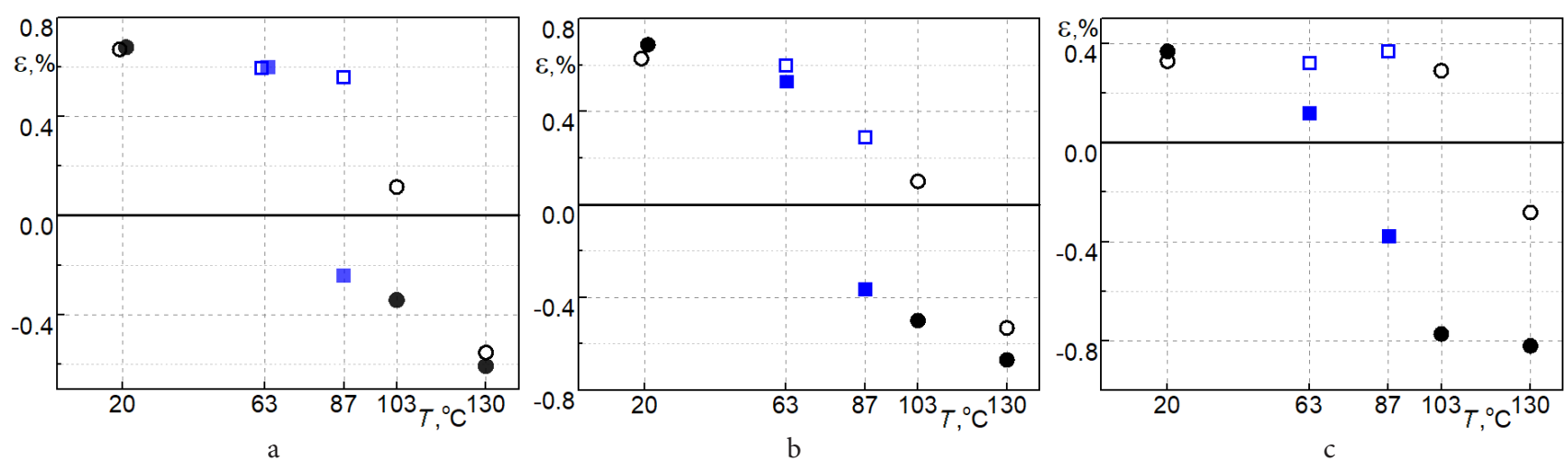

Fig. 6. Dependences of TWSM on test temperature. $\odot, \square-$ quasi-static compression $\bullet$, $\square-$ dynamic compression. $5 \%$ residual strain, dynamic compression at a strain rate of $500 \mathrm{~s}^{-1}(\mathrm{a}) ; 10 \%$ residual strain, dynamic compression at a strain rate of $1200 \mathrm{~s}^{-1}(\mathrm{~b}) ; 17 \%$ residual strain, dynamic compression at a strain rate of $1600 \mathrm{~s}^{-1}(\mathrm{c})$.
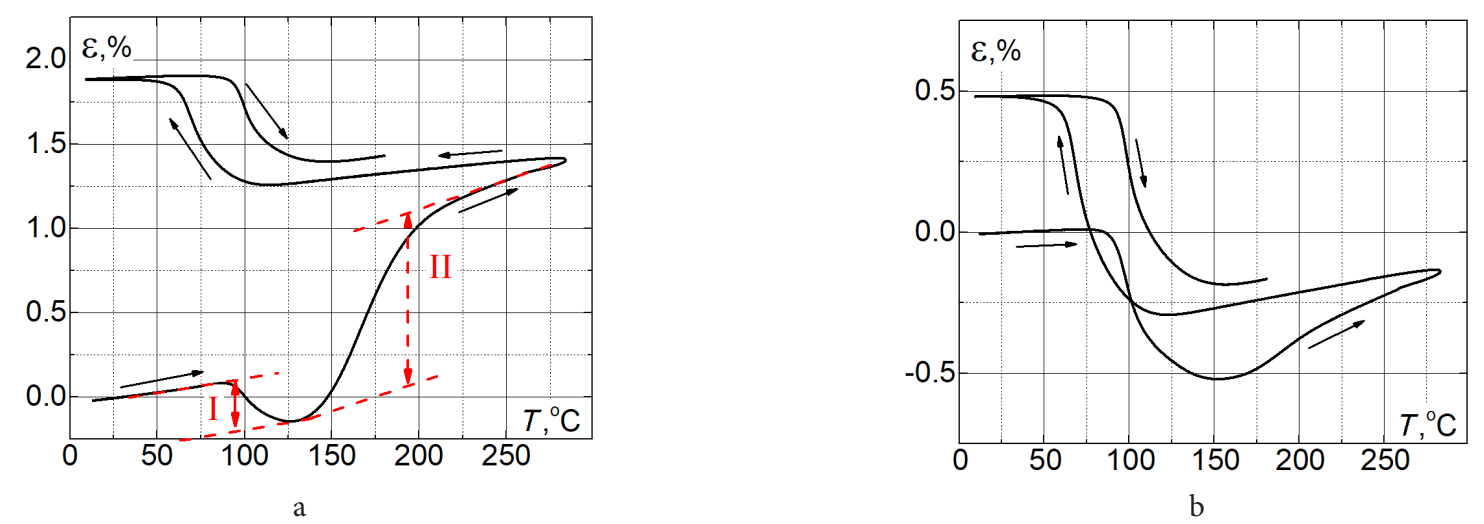

Fig. 7. $\varepsilon(T)$ curves after compression at $130^{\circ} \mathrm{C}$ up to $10 \%$ residual strain. Quasi-static (a) and dynamic (b) compression. (I - austenitic TWSM, II - SME).

As suggested above, the formation of the stress-induced martensite is sensitive to the strain rate. The proportion of the stress-induced martensite obtained in dynamic loading is less than in the quasi-static loading. For instance, we observe the pure austenitic TWSM after dynamic compression at $130^{\circ} \mathrm{C}$ (Fig. $7 \mathrm{~b}$ ). An increase in the residual strain from 5 to $17 \%$ leads to an increase in the austenitic TWSM from 0.6 to $0.9 \%$ (Fig. 6).

\section{Conclusion}

This study shows that the strain rate has a significant influence on the functional properties of the NiTi alloy. In some cases, the strain-temperature curves after quasi-static and dynamic compression are completely different.

- The SME values after high strain rate compression are less than after quasi-static compression. For instance, the one-way shape memory effect after the high strain rate compression at room temperature up to $17 \%$ residual strain is $25 \%$ less.

- The martensitic TWSM behavior is similar to the SME behavior, except for the case when pre-straining is performed at room temperature. With an increase in the strain rate, the SME decreases, and the irreversible strain increases. Consequently, the martensitic TWSM after compression at room temperature slightly increases (by about $10-12 \%$ in our experiments).

- The austenitic TWSM after the high strain rate compression occurs at lower test temperatures, and its value is higher than after quasi-static compression. For instance, the austenitic TWSM after the high strain rate compression at $130^{\circ} \mathrm{C}$ up to $17 \%$ residual strain is almost three times higher than in the quasi-static case.

- An unusual reversing shape memory effect appears after the high strain rate compression in the premartensitic, and the mixed-phase state. The strain-temperature curves consist of two sections directed oppositely. A similar behavior is observed after quasi-static deformation, but only at high pre-strain test temperatures (Fig. 7 a).

The results can be explained by the assumption that the structure of the material is inert: the martensite reorientation and the formation of stress-induced martensite, are not fully implemented with an increase in the strain rate. The proportion of the oriented martensite decreases with an increase in the strain rate. Thus, the SME is less after the high strain rate compression. For the same reason, the austenitic TWSM after high strain rate compression appears at lower test temperatures, and its value is higher than after quasistatic compression. The combination of pre-deformed phases causes the reversing shape memory effect upon heating.

Acknowledgements. The authors are grateful to the Russian Science Foundation for supporting this research (project № 19-79-00131). This research was performed at the Centre for Applied Aerodynamics, Centre for Extreme States of Materials and Constructions, and the Centre for Thermogravimetric and Calorimetric Research of the Research Park of St. Petersburg State University. 


\section{References}

1. L. Petrini, F. Migliavacca. J. Metall. Art. 2011 (1), 501483 (2011). Crossref

2. A. Razov, A. Cherniavsky. J. de Physique IV. 112 (10), 1173 (2003). Crossref

3. J. M. Jani, M. Leary, A. Subic, M. A. Gibson. Mater. Des. 56 (4), 1078 (2014). $\underline{\text { Crossref }}$

4. P. Lin, H. Tobushi, K. Tanaka, T. Hattori, A. Ikai. JSME Int. J. 39 (1), 117 (1996). Crossref

5. S. Nemat-Nasser, J.-Y. Choi. Acta. Mater. 53, 449 (2005). Crossref

6. S.-Y.Jiang, Y.-Q.Zhang. Trans. Nonferrous Met. Soc.China. 22, 90 (2012). Crossref

7. A.M. Bragov, L.A. Igumnov, A. Yu. Konstantinov, A. K. Lomunov, A.I. Razov. Adv. Struct. Mater. 103, 133 (2019). Crossref

8. Z. Yang, H. Wanga, Y. Huang, X. Ye, J. Li, C. Zhang, H. Li, B. Pang, Y. Tiana, C. Huang, G.Sun. Mater. Des. 191, 108656 (2020). Crossref

9. Y. Qiu, M. L. Young, X. Nie. Metall. Mater. Trans. A. 46 (10), 4661 (2015). Crossref

10. Y. Qiu, M. L. Young, X. Nie. Metall. Mater. Trans. A. 48,
601 (2017). Crossref

11. C. Elibol, M. F.-X. Wagner. Mater. Sci.Eng. A. 643, 194 (2015). Crossref

12. W. W. Chen, Q. Wu, J. H. Kang, N. A. Winfree. Int. J. Solids Struct. 38, 8989 (2001). Crossref

13. J. Zurbitu, R. Santamarta, C. Picornell, W.M. Gan, H.-G. Brokmeier, J. Aurrekoetxea. Mat. Sc. Eng. A. 528, 764 (2010). $\underline{\text { Crossref }}$

14. S.P. Belyaev, N.F. Morozov, A.I. Razov, A.E. Volkov, L.-L. Wang, S.-Q. Shi, S. Gan, J.-Y. Chen, S.-L. Dong. Mater. Sci. Forum, 394 - 395, 337 (2002). Crossref

15. A. Bragov, A. Danilov, A. Konstantinov, A. Lomunov, A. Motorin, A. Razov. Mater. Today Proc. 2 (Suppl. 3), S961 (2015). Crossref

16. H. Kolsky. Proc. Phys. Soc. London, Sect. B. 62, 676 (1949). Crossref

17. A.M. Bragov, L.A. Igumnov, A.Y. Konstantinov, A. K. Lomunov. Adv. Struct. Mat. 136, 11 (2020). Crossref

18. V. N. Khachin, V.E. Gyunter, D. B. Chernov. Phys. of Met. and Metall. 42 (3), 186 (1976).

19. A. Razov, A. Motorin, G. Nakhatova. J. Alloys Comp. 577, S164 (2013). Crossref 